\title{
OBJETIVOS DO DESENVOLVIMENTO SUSTENTÁVEL: O DIREITO HUMANO E O SUPORTE FÁTICO DA REDE DA VIDA
}

\section{OBJECTIVES OF SUSTAINABLE DEVELOPMENT: HUMAN RIGHTS AND THE FACTIC SUPPORT OF THE WEB OF LIFE}

\section{ELISAIDE TREVISAM}

Doutora em Filosofia do Direito pela Pontifícia Universidade Católica de São Paulo. Mestre em Direitos Humanos. Especialista em Direito do Trabalho e Processo do Trabalho. Professora Visitante Nacional no Programa de Mestrado em Direito da Universidade Federal de Mato Grosso do Sul - UFMS.

\section{JESSÉ CRUCIOL JUNIOR}

Mestrando no Programa de Mestrado em Direito da Universidade Federal de Mato Grosso do Sul - UFMS. Juiz de Direito do Estado de Mato Grosso do Sul.

\section{RESUMO}

Objetivo: $O$ artigo apresenta como objetivo analisar a relação entre 0 desenvolvimento sustentável e os direitos humanos, considerando-se a Agenda 2030 da Organização das Nações Unidas e os seus Objetivos do Desenvolvimento Sustentável (ODS)", com suas finalidades e a imprescindibilidade de implementação conjunta pela comunidade internacional.

Metodologia: Para atingir os fins esperados, a metodologia utilizada será documental e explorátoria, utilizando-se o método dedutivo, com caráter bibliográfico.

Resultados: O presente trabalho mostra como resultado a avaliação das premissas estabelecidas na pesquisa e demonstração da imprescindibilidade do modelo de desenvolvimento sustentável para a sustentabilidade da rede da vida, inclusive a vida humana digna e outros direitos fundamentais. 
Contribuições: A contribuição do presente trabalho visa, por fim, após analisar os Objetivos do Desenvolvimento Sustentável aprovados no âmbito da Organização das Nações Unidas no ano de 2015, descritos na Agenda 2030, apontar que a implementação desses objetivos, enquanto modelo socioeconômico, pelos Estados do globo em conjunto, é medida indispensável para a manutenção das condições da rede da vida como busca de efetivação dos direitos humanos em sua totalidade.

PALAVRAS-CHAVE: Desenvolvimento sustentável; direitos humanos; Agenda 2030.

\section{ABSTRACT}

Objective: To analyze the relationship between sustainable development and human rights, considering the United Nations Agenda 2030 and its Sustainable Development Goals (SDGs) ", with its purposes and the necessary joint implementation by the international community.

Methodology: To achieve the expected purposes, the methodology used will be documentary and exploratory, using the deductive method, with bibliographic feature.

Results: This paper shows as a result the evaluation of the premises established in the research and demonstration of the indispensability of the sustainable development model for the sustainability of the life network, including dignified human life and other fundamental rights.

Contributions: Finally, the purpose of this paper is, after analyzing the Sustainable Development Goals approved by the United Nations in 2015, described in Agenda 2030 , to point out that the implementation of these goals as a socioeconomic model by the States of the globe together, is an indispensable measure for the maintenance of the conditions of the network of life as a search for the realization of human rights in its entirety.

KEYWORDS: Sustainable development; human rights; Agenda 2030.

\section{INTRODUÇÃO}

A preocupação com o meio ambiente, especificamente quanto ao desenvolvimento sustentável, já vem se apresentando de longa data e pode-se verificar que, mesmo diante da existência de diversos documentos que tratam do tema em âmbito internacional, sejam esses documentos vinculantes (hard law ou jus 
cogens) ou não (soft law), o tema continua sendo debatido devido à necessidade de sua efetivação para proteção das gerações presentes e futuras. Recentemente, a Assembleia Geral das Nações Unidas aprovou, em setembro de 2015, a chamada "Agenda 2030 para o Desenvolvimento Sustentável" por meio da qual fixou 17 Objetivos do Desenvolvimento Sustentável (ODS), especificados em metas, visando a erradicação da pobreza e o desenvolvimento sustentável em suas três dimensões econômica, social e ambiental.

Tratando-se de uma problemática que deve ser refletida em consideração à proteção das gerações presentes e, principalmente, das futuras, o presente artigo tem por objetivo analisar a relação entre o desenvolvimento sustentável e os direitos humanos, o que levará a se desenvolver, inicialmente, a noção e conceituação de desenvolvimento sustentável, inclusive com base em documentos internacionais e literatura considerados marcos para o estabelecimento desse modelo. Para tanto, será traçada uma breve circunstaciação histórica com o intuito de compreensão do conceito e das razões do necessário desenvolvimento sustentável como direito humano.

Em um segundo momento, serão apresentados e analisados alguns conceitos e reflexões teóricas sobre o desenvolvimento sustentável para, posteriormente, ser apresentado o conceito de direitos humanos e, dentro dessa temátcia, refletir sobre o desenvolvimento sustentável e apossibilidade deste ser considerado, também, um direito humano e fundamental, tanto no âmbito internacional quanto no interno brasileiro.

Buscando discutir o assunto com profundidade e fundamentação, será apresentada a Agenda 2030 da Organização das Nações Unidas (ONU) e os seus Objetivos do Desenvolvimento Sustentável (ODS), com breve digressão histórica e análise sobre suas finalidades e a necessária implementação conjunta pela comunidade internacional.

Por fim, as premissas que forem estabelecidas nos itens citados serão postas em conjunto para se analisar sobre a imprescindibilidade do modelo de desenvolvimento sustentável para a sustentabilidade da rede da vida, inclusive a vida humana digna e outros direitos fundamentais. Com isso será possível entrever a 
indissociabilidade do direito ao desenvolvimento sustentável em relação aos demais direitos humanos e, consequentemente, a importância da implementação dos Objetivos do Desenvolvimento Sustentável como guia global de ação conjunta em prol da manutenção das condições para a contemplação da dignidade da vida em todos os seus termos.

Para alcançar os resultados esperados, a presente pesquisa é de cunho descritivo e exploratório, utilizando-se do método dedutivo. Quanto aos procedimentos, será de caráter bibliográfica e documental, analisando-se documentos internacionais, sites gerais, especializados e jornalísticos e contas em redes sociais relacionados ao desenvolvimento sustentável e direitos humanos.

\section{DESENVOLVIMENTO SUSTENTÁVEL}

O desenvolvimento sustentável tem sido uma preocupação constante não só para os ativistas em prol da proteção do meio ambiente mas também organismos internacionais globais (sistema ONU) e regionais (e.g. União Europeia), tanto quanto, mesmo que limitadamente, para os estados nacionais e organizações privadas (essas, via de regra, quando envolvidas em programas de responsabilidade socioambiental).

Outrossim, para compreender a questão, é bem de ver que a preocupação com o meio ambiente e mais especificamente com o desenvolvimento sustentável não é nova e surgiu de pesquisas e observações feitas sobre o modelo de desenvolvimento adotado pelos atores globais após a revolução industrial'1.

Segundo Edgar Morin (2013, p. 67): "A conjunção dos desenvolvimentos urbanos, técnicos, burocráticos, industriais, capitalistas e individualistas corrói internamente a civilização que essa mesma conjunção produziu e desenvolveu." Prossegue ele: "Assim, a técnica é o que permite aos seres humanos dominar as

${ }_{1}^{1}$ Disponível em: https://nacoesunidas.org/acao/meio-ambiente/. Acesso em: 09 maio 2019. 
energias naturais. Mas é também o que permite subjugar os humanos à lógica determinista, mecanicista, especializada, cronometrada, da máquina artificial."

O foco na ciência enquanto motor do desenvolvimento econômico após a Renascença levou ao desenvolvimento de tecnologias que mudaram a relação do homem com o meio, o trabalho e o outro. Com isso, o trabalho passou a ter um novo significado, pois do sistema feudal de guildas, corveia, vassalagem, etc, passou-se ao sistema moderno industrial, separando-se capital e força de trabalho. Além disso, a própria natureza do trabalho se alterou a partir da mecanização (exemplifica-se com o caso da máquina de fiar, em um grande galpão inglês concentrando centenas de trabalhadores em trabalhos segmentados e repetitivos, em relação ao trabalho manual do artesão pré-moderno).

Essa mudança na relação do homem com o meio passou a impactar ambos. O homem em sua significação enquanto tal, sob os valores do humanismo, do evolucionismo e do cientificismo. Já o meio, pela prevalência da lógica extrativista advinda do modelo científico mecanicista cartesiano e newtoniano (CAPRA; MATTEI, 2018), que levou ao limite a ideia de natureza subserviente/servil ao ser humano².

É certo que não se trata de um conceito puramente negativo, pois são inegáveis as conquistas na área da tecnologia, da medicina, entre outros. Morin (2013, p. 67), afirma que a produção em massa de produtos de uso e consumo e os preços mais acessíveis trouxe uma elevação do nível de vida. Porém, esse desenvolvimento - que há cinquenta anos parecia ainda mais providencial - faz pesar duas ameaças sobre a sociedade e os seres humanos: a exterior, que resulta da degradação ecológica dos meios de vida, e a interior, consubstanciada na degradação das qualidades de vida.

$\mathrm{O}$ resultado e os métodos desse novo modelo de desenvolvimento e organização social, dentre eles, a queima de combustíveis fósseis, a utilização de

\footnotetext{
${ }^{2}$ Essa ideia já estava presente no texto religioso judaico-cristão do velho testamento (Gênesis 1:28): "Frutificai e multiplicai-vos, e enchei a terra, e sujeitai-a; e dominai sobre os peixes do mar e sobre as aves do céus, e sobre todo animal que se move sobre a terra.") e, com isso, influenciou grandemente o modelo de desenvolvimento ocidental, fortemente dominado pelo cristianismo desde ao menos a conversão do imperador romano Constantino ou mesmo o banimento do paganismo pelo imperador Teodósio I.
} 
energia nuclear, o desflorestamento, a pressão populacional (com o que corroboraram os avanços - também de cunho científico - da medicina e no saneamento) e, consequentemente, a maior pressão por alimentos e água potável, tudo calcado na lógica extrativista, impactaram fisicamente o meio ambiente e suas relações de interdependência. A poluição passou a ser visível na água e no ar das grandes cidades, avançando sobre as pequenas e o campo, tanto quanto costas e rios.

Edgar Morin (2013, p. 67) conclui que a conjunção dos desenvolvimentos urbanos, técnicos, burocráticos, industriais, capitalistas e individualistas corrói internamente a civilização que essa mesma conjunção produziu e desenvolveu. Em algum momento, portanto, esse estranhamento gerado pela perturbação do meio ambiente e da qualidade de vida das pessoas, tornou-se consciência e, enfim, também ciência.

Corroborando com essa ideia, Braga (2015, p. 16) afirma que a tecnologia modifica o agir humano e, em contrapartida, as éticas tradicionais teriam se tornado incapazes de fazer frente aos desafios da sociedade tecnológica. Afirma que, desse modo, seria necessário o desenvolvimento de uma ética que atinasse para a responsabilidade humana sobre a continuidade da existência humana sobre a terra.

O sítio eletrônico da Organização das Nações Unidas para o Brasil (ONU Brasil) destaca a publicação do livro "A Primavera Silenciosa" de Rachel Carson, em 1962, como um momento crucial para a tomada de consciência ambiental. Do mesmo modo, outro marco se deu quando, em 1972, a ONU convocou a Conferência das Nações Unidas sobre o Meio Ambiente, que se realizou em Estocolmo (Suécia), da qual resultou um Manifesto Ambiental com 19 princípios para a atualidade.

Importante visão crítica sobre o modelo de desenvolvimento vigente e seus pressupostos é a chamada "ecologia profunda". Segundo Fritjof Capra deve-se ao noruegês Arne Naess a ideia de ecologia profunda, a qual "[...] reconhece a interdependência fundamental de todos os fenômenos, e o fato de que, enquanto indivíduos e sociedades, estamos todos encaixados nos processos cíclicos da natureza" (CAPRA, 2006, p. 25).

A ecologia profunda, ao reconhecer a interdependência dentro de toda a rede da vida se contrapõe a ecologia rasa, que é antropocêntrica e visa proteger a natureza 
para o bem do ser humano, conferindo-lhe, com isso, caráter instrumental em relação ao homem. Logo, para a ecologia rasa o ser humano ainda é visto separadamente de seu meio, pressuposto que divide com a lógica mecanicista que presidiu o avanço científico da modernidade. A união entre o eu e a natureza que caracteriza a ecologia profunda (CAPRA, 2006, p. 29), implica que o vínculo entre uma percepção ecológica do mundo e o comportamento correspondente não é uma conexão lógica, mas psicológica (FOX apud CAPRA, 2006, p. 29).

Reafirmando o vínculo entre a subjetividade humana e a ecologia, Felix Guatarri por sua vez desenvolveu a ideia de ecosofia, que se consubstancia na articulação ético-política entre os três registros ecológicos, quais sejam, o do meio ambiente, o das relações sociais e o da subjetividade humana (GUATARRI, 2012, p. 8). Para Guatarri, então, é condição para a solução da crise ecológica a revolução não só concernente às forças visíveis em grande escala, mas também aos domínios moleculares de sensibilidade, inteligência e desejo (GUATARRI, 2012, p. 9).

Desse modo, com tais autores, percebe-se não só a inexorabilidade da preocupação ambiental enquanto suporte da vida em geral, mas a necessidade de ação efetiva no âmbito de políticas públicas ambientais e sistêmicas, inclusive na mudança de paradigmas científicos e sociais (CAPRA, 2006, p. 24).

Sendo assim, o desenvolvimento econômico um modelo social e psicológico arraigado há cerca de três séculos, inicialmente na Europa e espalhando-se desde então pelo globo, a sustentabilidade da rede da vida só pode advir de uma mudança na forma de sua concepção e prática efetiva, no mínimo para condicionar o desenvolvimento a modelos e práticas que conservem a sustentabilidade dos sistemas (e, com isso, da rede da vida).

Por fim, não se pode deixar de citar que, além dos que foram acima referidos, muitos outros autores e organizações foram e são responsáveis por pensar uma nova forma de desenvolvimento, centrando-se na sustentabilidade da vida e na manutenção do equilíbrio dos sistemas.

Partindo dessa fundamentação, pode-se afirmar que o desenvolvimento sustentável é o desenvolvimento que encontra as necessidades atuais sem comprometer a habilidade das futuras gerações de atender suas próprias 
necessidades. Esse conceito, lavrado em termos simples e de fácil compreensão, é ainda tido como modelo para definir o que seja desenvolvimento sustentável.

Trata-se de um conceito constante no relatório "Nosso Futuro Comum", de abril de 1987, elaborado pela Comissão Mundial sobre o Meio Ambiente e Desenvolvimento, também conhecida por "Comissão Bruntland, a qual fora convocada pelo Secretário-Geral da Organização das Nações Unidas (ONU) em 1983².

$O$ aceleramento do processo de evolução tecnológica baseado no modelo extrativista (CAPRA; MATTEI, 2018) tem levantado questões importantes sobre o desenvolvimento e o crescimento econômico (MORIN, 2013) e seu impacto no meio ambiente. Por outro lado, a par de diversos documentos internacionais tratando de desenvolvimento sustentável e combate às mudanças climáticas, como o relatório "Nosso Futuro Comum" (relatório Brundtland), a chamada "Agenda 21" adotada na "Cúpula da Terra" no Rio de Janeiro em 1992, o Protocolo de Quioto, os Objetivos do Milênio (ODM), o Acordo de Paris e os Objetivos do Desenvolvimento Sustentável (ODS), entre muitos outros, verifica-se que, ao fim e ao cabo, se consubstanciam em um simples "comprometimento" dos países em nível internacional, junto ao sistema ONU. Logo, não possuem força vinculante (hard law), mas apenas "moral"4 (soft law).

Assim, visões diferenciadas do direito, da sociedade e da ecologia tais como a Ecosofia de Felix Guatarri, o commoning de bens essenciais de Fritjof Capra e Ugo Mattei, a "via", entendida enquanto reformas nos mais amplos campos, proposta por Edgar Morin, entre outras, aparecem como forma de repensar o estado atual das coisas e propor mudanças com vistas a integrar o homem e suas instituições ao meio ambiente, protegendo a rede da vida como um todo não só para o presente, mas também para o futuro.

Retomando a apresentação de documentos internacionais sobre desenvolvimento sustentável, o relatório "Nosso Futuro Comum", que foi

\footnotetext{
${ }^{3}$ No entanto, segundo Capra (2006, p. 24) o conceito seria de Lester Brown, do Worldwatch Institute.

${ }^{4}$ Sem descurar da dificuldade em se pensar obrigação ou dever moral em relação a um ente ficcional (estado ou outro ente de direito internacional público).

${ }_{5}$ Pontua-se que, segundo consta do site da própria Organização das Nações Unidas para o Brasil (ONU Brasil), a escolha da médica, mestre em saúde pública e ex-Primeira Ministra da Noruega Gro Harlem Brundtland "foi uma escolha natural para este papel, à medida que sua visão da saúde ultrapassa as barreiras do mundo médico para os assuntos ambientais e de desenvolvimento humano".
} 
recepcionado pela Assembleia Geral das Nações Unidas em sua 96ª reunião plenária, em 11 de dezembro de 1987 e tratou de acomodar o interesse no desenvolvimento econômico com a proteção do meio ambiente visando as presentes e futuras gerações, é tido como um marco no tema, importância que advém não só de sua originalidade (sendo o primeiro do gênero) mas também de sua clareza e assertividade. Do relatório pode-se ainda colher trecho como o seguinte, que ajuda a clarificar o conceito de desenvolvimento sustentável adotado:

Na sua essência, o desenvolvimento sustentável é um processo de mudança no qual a exploração dos recursos, o direcionamento dos investimentos, a orientação do desenvolvimento tecnológico e a mudança institucional estão em harmonia e reforçam o atual e futuro potencial para satisfazer as aspirações e necessidades humanas.

A manifestação da Assembleia Geral das Nações Unidas que acolheu 0 relatório (Resolução 42/187) reconheceu a importância do tema e do relatório, constando preocupação com o desenvolvimento econômico e seus impactos, notadamente sobre as pessoas consideradas em condição de vulnerabilidade. A plenária afirmou concordar com a comissão [Brundtland] que, enquanto se tenta remediar problemas ambientais existentes, é imperativo influenciar as fontes desses problemas na atividade humana e na atividade econômica em particular, de modo a prover um desenvolvimento sustentável. Segundo Campos (2017, p. 183):

\begin{abstract}
O relatório confirmou a preocupação humana com os escassos recursos naturais, interligando o desenvolvimento com o respeito ao meio ambiente e a atuação do estado no incentivo a políticas públicas capazes de minimizar a pobreza. Assim, incentivou o crescimento econômico através da prática de atividades que proporcionem a sustentabilidade do ecossistema e do meio ambiente tanto nos países desenvolvidos quanto nos subdesenvolvidos, abandonando a velha teoria de que o primeiro deveria prevalecer sobre 0 segundo.
\end{abstract}

Porém, sem embargos, tal conceito, apesar de bem construído, não pode ser sobre-estimado, comportando atenção no modo de sua compreensão, até porque,

Disponível em: https://nacoesunidas.org/acao/meio-ambiente/. Acesso: 08 maio 2019. 
trata-se de princípio informador de políticas públicas globais. Em primeiro lugar, não se pode deixar de citar a questão sobre a crença no desenvolvimento econômico ilimitado (CAPRA, 2006, p. 25) em um mundo de recursos limitados. De forma enfática, Kenneth Boulding, citado por Morin (2013, p. 28) questiona: "qualquer um que acredite que um crescimento exponencial pode durar para sempre num mundo finito ou é um louco, ou um economista!". Não há dúvida da relevância de tal reflexão sobre o pressuposto do crescimento ilimitado, porém, maior aprofundamento refugiria ao âmbito desse trabalho.

Também enfrentando o conceito usual de desenvolvimento econômico, pontuam Capra e Mattei (2018, p. 63):

[...] o que é sustentado em um comunidade sustentável não é o desenvolvimento econômico, a vantagem competitiva ou qualquer outro critério usado pelos economistas, mas a totalidade de rede da vida da qual nossa sobrevivência depende a longo prazo.

Complementando, afirmam que "[...] a sustentabilidade não é uma propriedade individual, mas uma propriedade de toda uma rede de relações, e sempre diz respeito a toda uma comunidade" (CAPRA; MATTEI, 2018, p. 250). A crítica de Capra e Mattei, portanto, se dirige ao que se tem por "sustentável" no conceito de desenvolvimento sustentável. O conceito é formado de duas palavras, o substantivo "desenvolvimento" e o adjetivo "sustentável". São noções autônomas mas interligadas e que, juntas tem um conteúdo próprio, maior que somente a soma de seus conceitos, tal como defende o raciocínio sistêmico, inspirado na afirmação aristotélica de que o todo é maior que a simples soma das suas partes. Em sentido muito semelhante defendem Silveira e Sanches (2015, p. 148):

É o que ocorre com o direito ao desenvolvimento sustentável, fruto da junção entre o direito ao desenvolvimento e o direito ao meio ambiente sadio. A prática da sustentabilidade reflete a preocupação não só com 0 desenvolvimento, mas como a qualidade de vida da sociedade e das futuras gerações. 
Para Sarlet e Fensterseifer (2017, p. 126): "O desenvolvimento econômico, portanto, deve estar vinculado à ideia de uma melhoria substancial da qualidade de vida e, portanto, não apenas assentar em aspectos quantitativos no que diz com o crescimento econômico".

Com isso, pode-se ajustar o foco da defesa do desenvolvimento sustentável não para o crescimento econômico em si (que se sustentaria para continuar crescendo), mas para a suportabilidade da própria rede da vida. Logo, o crescimento econômico e o desenvolvimento devem se dar sem ofensa considerável à rede de sustentabilidade da vida. O foco é a salvaguarda dessa e não daquele. Essa conceituação, com eixo na sustentabilidade da vida, através ou mesmo a despeito do desenvolvimento, é a que será utilizada para os propósitos desse trabalho.

É certo que restam críticas quanto ao conceito de desenvolvimento sustentável. Morin (2013, p. 32), por exemplo, afirma que a tomada de consciência sobre a crise do desenvolvimento e seus males, inclusive o que se caracterizaria pela ocidentalização como arquétipo (o que também chamou de sociocentrismo ocidental), chegou apenas parcial e limitadamente na questão ecológica, atenuando-se a noção de desenvolvimento ao justapor-Ihe o conceito de "sustentável". Porém, o problema continuaria o mesmo. Chegou a afirmar ainda:

A ideia de "suportabilidade" (ou sustentabilidade) acrescenta ao
desenvolvimento um conjunto de ações voltado à salvaguarda da biosfera e,
correlativamente, à salvaguarda das gerações futuras. Essa noção contém
um componente ético importante, mas não poderia aperfeiçoar em
profundidade a própria ideia de desenvolvimento. Ela não faz senão suavizá-
la, recobri-la com uma pomada calmante. (MORIN, 2013, p. 32).

Nada obstante, sem tomar partido na questão da inexorabilidade, utilidade ou mesmo prescindibilidade do desenvolvimento em si, mas considerando que esse é tido geralmente como um dos grandes objetivos políticos dos estados e organizações econômicas internacionais (ex.: Organização Mundial do Comércio, Organização para a Cooperação e Desenvolvimento Econômico, Mercosul, etc), defende-se aqui, conforme já acima explicitado, que o modelo de desenvolvimento deve ser sustentável 
para a rede da vida, adaptando-se, para tanto, suas necessidades e métodos e, em alguns casos, objetivos.

\section{OS DIREITOS HUMANOS}

A Declaração Universal dos Direitos Humanos não definiu o conceito de Direitos Humanos. Segundo sítio da Organização das Nações Unidas: "Os direitos humanos são direitos inerentes a todos os seres humanos, independentemente de raça, sexo, nacionalidade, etnia, idioma, religião ou qualquer outra condição"6. A conceituação não é infensa a crítica.

Conforme nos afirma Perez Luño (apud MIGUEL, 2014, p. 6), os direitos fundamentais podem ser definidos de três maneiras, quais sejam, a tautológica, segundo a qual os direitos humanos são aqueles próprios da pessoa apenas por ser pessoa; a formal, que ressalta não o conteúdo, mas a forma de reconhecimento desses direitos e seu regime jurídico específico; e a teleológica - pela qual se considera a essencialidade finalística desse direitos para a vida digna das pessoas.

Segundo a distinção analítica acima, pode-se notar, por exemplo, que a conceituação feita por Portela (2016, p. 819) considera ao mesmo tempo os caracteres tautológico e finalístico ao afirmar que direitos humanos são aqueles essenciais para que a pessoa seja tratada com dignidade que lhe é inerente e que pertence a toda as pessoas "da espécie humana", sem qualquer distinção. Do mesmo modo, percebe-se a conceituação tautológica e formal feita por Mazzuoli (2015, p. 895 e 897) ao afirmar que basta a condição de ser pessoa humana para poder reivindicar seus direitos violados tanto no plano externo quanto interno e que direitos humanos são aqueles inscritos em tratados ou decorrentes de costumes internacionais, ou seja, que já ascenderam ao Direito Internacional Público.

De forma mais profunda, Jose Luiz Bolzan de Morais (apud OLIVEIRA, p. 383) conceitua os direitos humanos assim:

${ }^{6}$ Disponível em https://nacoesunidas.org/direitoshumanos/. Acesso em: 21 maio 2019. 
Resumidamente poderíamos dizer, então, que os direitos humanos, como conjunto de valores históricos básicos e fundamentais, que dizem respeito à vida digna jurídico-político-psíquico-físicoeconômica e afetiva dos seres humanos e de seu habitat, tanto daqueles do presente quanto daqueles do porvir, surgem sempre como condição fundante da vida, impondo aos agentes político-jurídico-econômico-sociais a tarefa de agirem no sentido de permitir e viabilizar que a todos seja consignada a possibilidade de usufruílos em benefício próprio e comum ao mesmo tempo.(RÚBIO et all, 2010, p. 215)

Complexo também o conceito de Peces-Barba (apud MIGUEL, 2014, p. 7):

São faculdades que o direito atribui a pessoa e aos grupos sociais, expressão de suas necessidades relativas à vida, liberdade, igualdade, participação política ou social, ou a qualquer outro aspecto fundamental que afete o desenvolvimento integral das pessoas em uma comunidade de homens livres, exigindo o respeito ou a atuação dos demais homens, dos grupos sociais e do Estado, e com garantia dos poderes públicos para restabelecer seu exercício em caso de violação ou para realizar sua prestação.

Esses dois últimos conceitos se mostram bastante ricos e adequados, porque evitam a mera tautologia ou mesmo a limitação dos direitos fundamentais apenas aqueles já formalmente reconhecidos em documentos internacionais ou mesmo em Constituições nacionais.

Quanto a isso, consideramos mesmo indispensável atentar para o caráter histórico dos direitos humanos, já que cada momento político-econômico-social na história é acompanhado de certos valores maiores tidos por minimamente necessários para que se tenha uma vida digna, de modo que, concretamente falando, o rol dos direitos humanos vai se ampliando com o passar do tempo (processo que não se pode dizer esteja esgotado ${ }^{7}$ ).

É certo que, conforme diz Mazzuoli (2015, p. 896) nos dias atuais é difícil existir uma gama de direitos conhecíveis que não conste de algum documento escrito, porém, isso não infirma que a variedade, historicidade e inexauribilidade dos direitos humanos torne impossível uma compilação completa e definitiva.

${ }^{7}$ No tocante a inexauribilidade dos direitos humanos ver Mazzuoli (2015, p. 900). 
Por fim, mas não menos importante, concorda-se com a crítica de Martins e Dimoulis sobre a impropriedade da conceituação tautológica dos direitos humanos, a qual, pela importância será citada integralmente:

\begin{abstract}
A 'natureza do homem' só se encontra nos dados de sua constituição biológica. Nenhum direito ou obrigação, nenhuma regra de conduta social pode ser deduzida da natureza humana. Isso é de fácil comprovação histórica já que o "homem" viveu sob os mais variados regimes sociais e isso não seria possível se a sua natureza fosse sempre a mesma ou se tal suposta natureza fosse determinante para a outorga de direitos, que nada mais seria do que 0 seu reconhecimento pelo poder político. Não se pode imaginar uma sociedade na qual os homens não durmam ou não se alimentem, pois isso faz parte de sua verdadeira natureza. De outro lado, há muitas sociedades que privaram vastos grupos de seres humanos de liberdade, instituindo a desigualdade política a despeito de suposta igualdade ou mesmo em razão do reconhecimento de suposta desigualdade natural. (MARTINS; DIMOULIS, 2014, p. 45)
\end{abstract}

Destarte, dito isso, para os fins do presente trabalho se adotará a conceituação teleológica dos direitos humanos, conforme as propostas de José Luiz Bolzan e Peces-Barba citadas, mas sem, no entanto, desconsiderar o papel integrador das distinções tautológicas e formais na definição ou interpretação do que seja direitos humanos.

No mais, e de um modo geral, com base no que trata HARARI (2017), no sentido que o ser humano (homo sapiens) é criador de sua própria realidade, alterando significativamente o mundo à sua volta devido ao trabalho em conjunto (cooperativo) e sua capacidade de atuar por obras de sua própria mente (lidando não apenas com necessidades físicas básicas como alimento, água, luz do sol, etc) é que se põe o embasamento inicial da pesquisa, verificando-se que a atitude criadora e transformadora da realidade do ser humano levou, factualmente, a um modelo de desenvolvimento prejudicial à manutenção da qualidade de vida na terra (que é seu ambiente fechado, ao menos até agora).

Não obstante, somente o próprio sapiens tem a capacidade de trabalhar, do mesmo modo unido, para mudar esse seu modo próprio de desenvolvimento. Com isso, a mesma capacidade cooperativa que criou o modo de vida poluidor é a única 
força palpável capaz de impor uma mudança significativa nos rumos da humanidade, de modo a preservar o ambiente para as futuras gerações.

Com base nisso, é preciso, como consta do preâmbulo da Declaração Universal dos Direitos Humanos, reafirmar essa "fé" nos direitos humanos, nesse caso especificamente no direito humano básico e condicionante relativo a um meio ambiente ecologicamente equilibrado e a um modelo de desenvolvimento sustentável que possa garantir um futuro digno a atual e futuras gerações.

\subsection{DESENVOLVIMENTO SUSTENTÁVEL: DIREITO HUMANO OU DIREITO INDISPENSÁVEL AOS DIREITOS HUMANOS?}

A Declaração Universal dos Direitos Humanos, de 1948, não se refere ao meio ambiente ou ao desenvolvimento sustentável em qualquer de suas disposições ou preâmbulo. Naquele momento, o meio ambiente, sua preservação e a interdependência com a vida humana não integrava o rol das preocupações políticas na agenda ocidental para o globo.

Apesar de haver quem já atribua ao art. 12 do Pacto Internacional de Direitos Econômicos, Sociais e Culturais de 1966 a preocupação internacional, ainda que indireta, ao meio ambiente sadio e equilibrado (MÖLLER; MUNIZ, 2007, p. 272), segundo Mazzuoli (2017, p. 178) e Portela (2016, p. 454) a proteção ao meio ambiente somente passou a fazer parte da agenda internacional a partir da Declaração de Estocolmo, de 1972.

Do mesmo modo, os autores citados afirmam que esse foi o marco da ascensão do direito ao meio ambiente equilibrado ao status de direito humano. A partir da Declaração de Estocolmo o meio ambiente deixou de ser visto como algo dissociado da humanidade (PORTELA, 2016, p. 455). A propósito, o Princípio 1 da Declaração de Estocolmo dispõe:

O homem tem o direito fundamental à liberdade, à igualdade e ao desfrute de condições de vida adequadas em um meio ambiente de qualidade tal que the permita levar uma vida digna e gozar de bem-estar, tendo a solene obrigação 
de proteger e melhorar o meio ambiente para as gerações presentes e futuras. ${ }^{8}$

Conforme noticia Mazzuoli (2015, p. 1102) O Documento de Antecedentes $\mathrm{n}^{\circ}$ 1 e 2, denominado Questões Ambientais e Direitos Humanos nos Tratados Multilaterais Adotados entre 1991 e 2001, Dinah Shelton expôs principais instrumentos internacionais que trazem explicitamente a inter-relação dos direitos humanos com a proteção do meio ambiente, entre eles, além do Princípio 1 da Declaração de Estocolmo, estariam a Convenção de Aarhus, a Convenção das Nações Unidas sobre os Direitos da Criança de 1989, a Carta Africana dos Direitos Humanos e dos Povos, A Carta dos Direitos Fundamentais da União Europeia, entre outros.

No âmbito Regional americano o Protocolo Adicional à Convenção Americana sobre Direitos Humanos em Matéria de Direitos Econômicos, Sociais e Culturais (Protocolo de San Salvador) prevê que toda pessoa tem direito a viver em um meio ambiente sadio e que os Estados-Partes tem o dever de promover a proteção, preservação e melhoramento do meio ambiente.

Nestes termos, pode-se dizer com razoável segurança que o direito ao meio ambiente equilibrado é um direito humano. Da mesma forma, internamente no Brasil, o art. 225 da Constituição da República Federativa do Brasil prevê que todos tem o direito ao meio ambiente ecologicamente equilibrado, reconhecendo expressa e claramente sua essencialidade e impondo ao Poder Público e à coletividade o dever de defende-lo e preserva-lo para as presentes e futuras gerações.

Portanto, também na esfera interna brasileira, pode-se dizer que o meio ambiente equilibrado é um direito fundamental. Quanto ao desenvolvimento sustentável, a solução é mais problemática, contudo, conforme explica CAMPOS (2017, p. 175-176):

[...] a partir do artigo 225 da Constituição Federal, pode se abstrair o princípio do desenvolvimento sustentável. O entendimento doutrinário está no fato de

8 Disponível em http://www.direitoshumanos.usp.br/index.php/meio-ambiente/declaracao-deestocolmo-sobre-o-ambiente-humano.html. Acesso: 18 maio 2019. 
que esse princípio está ligado com o direito à vida que está expressa no artigo $5^{\circ}$ caput da Constituição e também na Declaração Universal dos Direitos Humanos, em seu artigo 3o; ou seja, trata-se do direito à sadia qualidade de vida um dos requisitos indispensáveis a existência digna do ser humano.

Sarlet e Fensterseifer (2017, p. 119), de sua parte, consideram o desenvolvimento sustentável um princípio em matéria ambiental. Quanto a isso, não cabe aqui entrar na discussão sobre a natureza e função dos princípios, o que impactaria a categorização do desenvolvimento sustentável conforme a visão desses autores.

O princípio 4 da Declaração do Rio de 1992 dá pista para a categorização do desenvolvimento sustentável ao dispor que a fim de alcançar o desenvolvimento sustentável, a proteção do ambiente deverá constituir-se como parte integrante do processo de desenvolvimento e não poderá ser considerada de forma isolada. Com isso, tem-se a ideia de que o desenvolvimento sustentável é algo a ser alcançado, uma meta ou objetivo. Porém, mais do que isso, o que se deve considerar é que o desenvolvimento sustentável é um modelo econômico-social, com reflexo no mundo jurídico.

Apesar do o princípio 3 da Declaração do Rio dar a entender que se trataria de um modelo de desenvolvimento, apenas limitado pela sustentabilidade ${ }^{9}$, como se essa servisse apenas de limite externo aquele, como visto anteriormente, o desenvolvimento sustentável deve ser um modelo sistêmico de desenvolvimento econômico e humano, cuidando da erradicação da pobreza, diminuição das desigualdades e de manter o equilíbrio do meio ambiente e a sustentabilidade da rede da vida como um todo.

Assim, considera-se o modelo social-econômico de desenvolvimento sustentável indispensável não só à implementação do direito humano ao meio ambiente equilibrado mas ao próprio direito à vida digna. A propósito disso:

9 Declaração do Rio sobre meio Ambiente e Desenvolvimento: Princípio 3 - "O direito ao
desenvolvimento deve ser exercido de modo a permitir que sejam atendidas equitativamente as
necessidades de desenvolvimento e de meio ambiente das gerações presentes e futuras." Disponível
em:http://www.meioambiente.pr.gov.br/arquivos/File/agenda21/Declaracao_Rio_Meio_Ambiente_Des
envolvimento.pdf. Acesso: 21 maio 2019. 
No sentido empregado pelo art. 225, caput, do texto constitucional, o direito ao meio ambiente ecologicamente equilibrado é um prius lógico do direito à vida, sem o qual esta não se desenvolve sadiamente em nenhum dos seus desdobramentos. É dizer, o bem jurídico vida depende, para a sua integralidade, entre outros fatores, da proteção do meio ambiente com todos os seus consectários, sendo dever do Poder Público e da coletividade defendê-lo e preservá-lo para presentes e futuras gerações. (MAZZUOLI, 2007, p. 182).

Com essa base teórica e, aceitando-se a caracterização teleológica dos direitos fundamentais conforme proposta por Perez Luño acima citada, ao se reconhecer a imprescindibilidade do modelo de desenvolvimento sustentável para a vida e, de todo modo, para a rede da vida como um todo, é possível caracterizar funcionalmente o desenvolvimento sustentável como um direito humano por si, independente de seu reconhecimento formal em documentos internacionais sobre direitos humanos (conceito formal de direitos humanos).

Antes de mais nada, como referência teórico-política, no que tange diretamente ao desenrolar do reconhecimento de gerações ou dimensões de direitos humanos fundamentais pela comunidade internacional, após o reconhecimento dos direitos voltados à liberdade (primeira dimensão, de cunho liberal) e à igualdade (segunda dimensão, de cunho social) chegou-se aos direitos voltados à solidariedade, de cunho transindividual, dando forma à terceira dimensão desses direitos. Aqui reconhecem-se como essenciais os direitos ao meio ambiente, ao desenvolvimento ou progresso, à autodeterminação dos povos, entre outros. De acordo com Alves; Cunha e Souza (2018, p. 495):

\begin{abstract}
Uma outra forma de se conceber o desenvolvimento é reconceituá-lo a partir da apropriação efetiva das três gerações de direitos humanos: direitos políticos, civis e cívicos; direitos econômicos, sociais e culturais, entre os quais o direito ao trabalho digno, criticamente importante; direitos coletivos ao meio ambiente e ao desenvolvimento. Igualdade, equidade e solidariedade estão inseridas no conceito de desenvolvimento, e são condições para que o pensamento econômico sobre 0 desenvolvimento se diferencie do economicismo redutor. $\mathrm{O}$ objetivo maior é promover a igualdade e melhora das vantagens daqueles que vivem em más condições, reduzindo a pobreza.
\end{abstract}

Passado a considerar o modelo de desenvolvimento sustentável no âmbito interno brasileiro é preciso ressaltar que o art. 170 da Constituição Federal, ao tratar 
da ordem econômica, estabelece como princípio da ordem econômica a defesa do meio ambiente (inc. VI). Por sua vez, o art. $3^{\circ}$, que enumera os objetivos fundamentais da República traz entre eles o de garantir o desenvolvimento nacional (inc. II). Assim, e não havendo hierarquia entre normas constitucionais (DIMOULIS; MARTINS, 2014, p. 220.), o estado brasileiro deve garantir o desenvolvimento nacional e, concomitantemente, proteger o meio ambiente.

A proteção da vida, da saúde e da dignidade da pessoa é, fora de qualquer controvérsia, na Lei Maior brasileira, direitos fundamentais, restando claros esses dispositivos ao menos em seus primeiros sete artigos, sendo desnecessário aprofundar o tema no âmbito desse trabalho.

Igualmente, a proteção do meio ambiente está presente direta ou indiretamente em vários outros dispositivos da Constituição brasileira como, por exemplo, o art. 23, incisos VI e VII, que estabelece ser competência comum dos entes promover a proteção do meio ambiente, o combate a poluição e a preservação das florestas, fauna e flora. Do mesmo modo, a proteção do modelo de desenvolvimento econômico (ex.: art. 23, incisos VIII e XI).

Logo, no âmbito nacional brasileiro, atendo-se ao texto da Constituição Federal e suas intersecções (princípio da unicidade da Constituição), o qual dá ênfase ao desenvolvimento nacional como objetivo fundamental ao lado da essencialidade da proteção do meio ambiente, pode-se dizer que há um direito constitucional fundamental coletivo ao modelo de desenvolvimento sustentável, equilibrando-se o desenvolvimento nacional e a proteção ambiental.

Assim, no âmbito internacional ou interno brasileiro, devido ao caráter instrumental indispensável do desenvolvimento sustentável em relação aos direito à vida, saúde, meio ambiente ecologicamente equilibrado, entre outros, é possível entrever, tanto no conceito teleológico dos direitos humanos quanto da análise de dispositivos constitucionais sobre desenvolvimento, vida, dignidade e proteção do meio ambiente, que se trataria de um direito humano fundamental (de terceira dimensão) de fruição coletiva.

Nada obstante, é preciso mesmo atentar que, ainda que se conclua que a ausência de reconhecimento formal no âmbito internacional ou que o desenvolvimento 
sustentável não pode ter a estrutura de um direito na Constituição Federal ou, por qualquer motivo, não possa ele ser tido por direito humano, não deve restar dúvida até aqui de que esse modelo é imprescindível para a sustentabilidade da rede da vida (incluindo a humana) de modo que se trata de um modelo, no mínimo, imprescindível aos direitos humanos (à vida digna, saúde, meio ambiente equilibrado, etc). Assim, sua implementação deve, de qualquer modo, estar no mesmo patamar dos direitos humanos na agenda global, sob pena de se deixar perecer a qualidade da vida pela omissão.

\section{A AGENDA 2030 E OS OBJETIVOS DO DESENVOLVIMENTO SUSTENTÁVEL}

Os Objetivos do Desenvolvimento Sustentável (ODS) são produto - e o próprio cerne - da "Agenda 2030", aprovada em consenso pelos delegados dos Estados-membros na Assembleia Geral da Organização das Nações Unidas em 2015.

A Agenda 2030, conforme definido em seu próprio texto, é um plano de ação internacional voltado às pessoas, ao planeta e à prosperidade (BRASIL, 2016), sendo visto como um guia para as ações da comunidade internacional nos próximos anos (PLATAFORMA AGENDA 2030, 2019). Do mesmo modo, a Agenda afirma buscar fortalecer a paz universal com mais liberdade e reconhecer que a erradicação da pobreza em todas as suas formas e dimensões, incluindo a pobreza extrema, é o maior desafio global e um requisito indispensável para o desenvolvimento sustentável.

Através desses eixos (pessoas, planeta e prosperidade) buscou-se fortalecer a parceria colaborativa (ONU, 2015) global para alcançar as ambiciosas metas fixadas para cada Objetivo do Desenvolvimento Sustentável. Com isso, é preciso ressaltar que, simbolica e formalmente, os membros da Organização das Nações Unidas reconheceram que, em um mundo globalizado, problemas como os relativos à pobreza, meio ambiente, etc, são globais e, por isso, precisam de soluções também globais, o que só se alcança coletivamente, por meio do que chamou-se de parceria colaborativa e o comprometimento de todos os países manifestado naquele momento. 
De forma bastante enfática, apesar de concisa, o Secretário Geral da ONU afirmou: "A Agenda 2030 é a nossa Declaração Global de Interdependência" (PLATAFORMA AGENDA 2030, 2019).

Assim, a partir de 2015 (dando continuidade e ampliando a agenda anterior ODM - como se verá) os 193 países integrantes da Organização das Nações Unidas demonstraram formalmente a intenção de agir em conjunto visando a melhoria da qualidade de vida das pessoas, a erradicação da pobreza, o combate às mudanças climáticas e o fortalecimento da paz mediante o cumprimento de 17 Objetivos do Desenvolvimento Sustentável, minudenciados em 169 metas.

Os Objetivos do Desenvolvimento Sustentável contaram com programas anteriores que lhe deram suporte histórico e serviram de precedente. É preciso conhecer esses programas, mesmo que superficialmente, para bem entender 0 contexto e as bases dos ODS, auxiliando na valoração de suas finalidades.

Precedendo imediatamente os Objetivos do Desenvolvimento Sustentável, e nesse mesma linha de ação global colaborativa, houve os Objetivos de Desenvolvimento do Milênio (ODM) que visavam principalmente a redução da extrema pobreza e surgiram de uma série de cúpulas multilaterais realizadas nos anos 1990. A Declaração do Milênio e os ODM foram adotados pelos Estados-membros da ONU no ano 2000 (PLATAFORMA AGENDA 2030, 2019). Os oito objetivos do milênio (ODM) formaram o primeiro arcabouço global de políticas para o desenvolvimento e auxiliaram a formulação de políticas públicas governamentais até 2015, quando vieram a lume a Agenda 2030 e os Objetivos do Desenvolvimento Sustentável visando os próximos 15 anos.

Em 2010 a Cúpula das Nações Unidas sobre os Objetivos do Milênio demandou a aceleração na implementação dos ODM. O procedimento de discussão e trabalho desencadeado por tal demanda culminou na apresentação do relatório "Uma Vida Digna para Todos", que foi o pontapé inicial para a nova agenda (Agenda 2030).

Do mesmo modo, por sua vez, os Objetivos do Milênio foram precedidos da "Agenda 21". A Agenda 21 foi a primeira carta de intenções a promover um novo padrão de desenvolvimento para o século XXI (PLATAFORMA AGENDA 2030, 2019) 
e fora aprovada na Conferência das Nações Unidas sobre o Meio Ambiente e o Desenvolvimento realizada no Rio de Janeiro em 1992, que restou conhecida por "Rio 92".

Segundo Portela (2016, p. 445) a Agenda 21 se tratou de um programa de ação que visa garantir o desenvolvimento econômico em condições equitativas para toda a humanidade, observando-se parâmetros de respeito ao meio ambiente. Naquela ocasião fora aprovada a Declaração do Rio sobre Meio Ambiente, por meio da qual: "[...] os países concordaram com a promoção do desenvolvimento sustentável, com foco nos seres humanos e na proteção do meio ambiente como partes fundamentais desse processo." (PLATAFORMA AGENDA 2030, 2019).

Vinte anos depois, representantes de 193 países voltaram ao Rio de Janeiro (Rio+20) para avaliar os progressos até ali, as lacunas e os desafios emergentes (PLATAFORMA AGENDA 2030, 2019). Dessa reunião resultou o documento "O Futuro que Queremos", que também acabou (juntamente com o relatório O Caminho para a Dignidade em 2030) por servir de apoio para a formulação dos Objetivos do Desenvolvimento Sustentável e a Agenda 2030.

A Agenda 2030 para o Desenvolvimento Sustentável, como antes dito, trouxe metas ambiciosas para atingir patamares adequados nas áreas econômica, social e ambiental em nível global. Para tanto, foram desenvolvidos 17 Objetivos de Desenvolvimento Sustentável (ODS), quais sejam: Redução da Pobreza; Fome Zero e Agricultura Sustentável; Saúde e Bem Estar; Educação de Qualidade; Igualdade de Gênero; Água Potável e Saneamento; Energia Acessível e Limpa; Trabalho Descente e Crescimento Econômico; Industria, Inovação e Infraestrutura; Redução das Desigualdades; Cidades e Comunidades Sustentáveis; Consumo e Produção Responsáveis; Ação Contra a Mudança Global do Clima; Vida na Água; Vida Terrestre; Paz, Justiça e Instituições Eficazes; Parcerias e Meios de Implementação. Todos esses objetivos foram minudenciados em metas.

Conforme consta da Agenda 2030, os objetivos são integrados e indivisíveis, sendo cruciais suas interconexões. Tal visão sistêmica retoma o que foi dito acima sobre o conceito de desenvolvimento sustentável tido como adequado para esse trabalho, superando o pensamento mecanicista e de fragmentação dos 
conhecimentos (MORIN, 2013) que guiou a ciência até parte do século XX (CAPRA; MATTEI, 2018).

Ocorre que, a despeito da importância estratégica dos Objetivos do Desenvolvimento Sustentável, do ponto de vista da obrigatoriedade jurídica é importante frisar que a Agenda 2030, que os veicula, configura uma declaração (adotada em Assembleia Geral das Nações Unidas), não tendo, portanto, força vinculante. Assim, conta apenas com a força simbólica da disposição (voluntária) dos países manifestada naquele momento em cooperar para um futuro sustentável (soft law ${ }^{10}$, portanto).

Porém, quando se fala da efetivação da agenda 2030 por parte dos Estados que firmaram o compromisso internacional, conforme explica SILVEIRA e PEREIRA (2018, p. 926), tem-se que considerar que:

[...] evidentemente não se pode desconsiderar o fato de que a realização de alguns direitos humanos requer a disponibilização de recursos financeiros, 0 que torna patente a disparidade de condições entre os países pobres e os países ricos para o atingimento dos objetivos e metas da Agenda 2030. Por tal razão, é de fundamental importância que tantos os Estados pobres quanto os seus cidadãos tenham acesso a recursos financeiros de modo facilitado e sejam redefinidos alguns pontos relativos à dívida pública para não prejudicar a concretização dos ODS.

Ainda assim, devido à importância de tais objetivos globais e a especificidade de suas metas, visando um futuro mais justo, igualitário e sustentável às gerações presentes e futuras, trata-se de documento de grande relevância e que merece atenção especial da comunidade global, envolvendo governos, indivíduos e organizações não-governamentais.

Conforme o que foi dito acima, verifica-se que o desenvolvimento sustentável, enquanto modelo econômico-social, independentemente de ser tido como direito humano (o que se defende aqui) ou apenas direito/modelo essencial aos direitos

\footnotetext{
${ }^{10}$ Segundo o Institut de Droit International seriam textos adotados pelos sujeitos de direito internacional adotam que, apesar de gerarem obrigações em suas relações mútuas, são desprovidos, pela vontade expressa ou tácita das partes, de caráter jurídico (Mazzuoli, 2015, p. 183). Ainda segundo Mazzu oli (2015, p. 186), o que difere a soft law das demais normas seria o fato de ser ela um produto jurídico inacabado, voltada a assunção de compromissos futuros e de ser regida por um sistema de sanções distinto do tradicional, sendo seu cumprimento mais uma recomendação que uma obrigação.
} 
humanos é indispensável à rede da vida, demandando ainda uma nova visão sobre a relação das pessoas com seu meio.

Tendo em conta essa indispensabilidade do meio ambiente equilibrado para a vida digna, que depende grandemente da adoção de um modelo de desenvolvimento sustentável, superando o modelo de desenvolvimento extrativista e a lógica mecanicista em favor de um raciocínio sistêmico, é necessário apoiar o esforço internacional para tanto, consubstanciado atualmente na ação conjunta levada a cabo por meio dos Objetivos do Desenvolvimento Sustentável da Agenda 2030.

Seguindo-se esse esforço global conjunto, devidamente formalizado e planejado, é possível implementar um modelo adequado que preserve a rede da vida e sua dignidade, mesmo que sem descurar do sistema desenvolvimentista que predomina ainda hoje (sem olvidar a crítica de MORIN, 2013, p. 32).

Com isso, avulta de importância o cumprimento pelos estados, organizações e indivíduos das metas constantes de cada um dos Objetivos do Desenvolvimento Sustentável, o que deve consubstanciar uma mudança de paradigma econômicosocial e pessoal (GUATARRI, 2012, p. 9; FOX apud CAPRA, 2006, p. 29) visando a manutenção e melhora das condições de vida da presente geração e resguardo dos direitos e possibilidades dignas das futuras.

Consequentemente a implementação dos Objetivos do Desenvolvimento Sustentável é não só hábil a promover um modelo de desenvolvimento econômico sustentável ambientalmente mas, imprescindível para a manutenção da rede da vida e da dignidade humana com fins de efetivação dos Direitos Humanos em todas a suas formas.

\section{CONCLUSÃO}

Conforme a reflexão do texto e com apoio de alguns importantes pensadores, foi possível concluir que o sustentável no conceito de desenvolvimento sustentável não se refere ao crescimento econômico em si (que se sustentaria para continuar crescendo), mas a suportabilidade da rede da vida. 
Do mesmo modo, pode-se aurir a indissociabilidade do modelo de desenvolvimento sustentável para que a humanidade possa conviver harmonicamente com o meio ambiente que habita, sendo parte dele, superando-se, com isso, a lógica mecanicista que via o homem separado do ambiente.

Sem muitas divergências, viu-se que o meio ambiente equilibrado é condição para a vida digna e um direito humano fundamental reconhecido no âmbito internacional e interno brasileiro. Quanto ao desenvolvimento sustentável, apontou-se a hermenêutica constitucional que indica tratar-se também de um direito fundamental no Brasil e, além disso, utilizando-se o conceito teleológico de Peres Luño, também se buscou demonstrar que se trata de um direito humano, devido à indispensabilidade desse modelo ecômico-social para a vida digna e, mais ainda, a sustentabilidade da rede da vida que serve de ambiente à [e portanto indissociável da] vida humana.

Procurou-se ainda demonstrar que sem um meio ambiente equilibrado, não há condições para a vida, ao menos de forma minimamente digna, o que só se poderá alcançar (em verdade manter) com a mudança do modelo de desenvolvimento para aquele sustentável nos moldes delineados com base em literatura especializada, para o que servem de modelo e guia específico os Objetivos do Desenvolvimento Sustentável.

Por fim, após analisar os Objetivos do Desenvolvimento Sustentável aprovados no âmbito da Organização das Nações Unidas no ano de 2015 descritos na Agenda 2030, apontou-se que a implementação desses objetivos, enquanto modelo socioeconômico, pelos países do globo em conjunto, é medida indispensável para a manutenção das condições da rede da vida como busca de efetivação dos Direitos Humanos em sua totalidade.

\section{REFERÊNCIAS}

ALVES, José Irivaldo; CUNHA, Belinda P. Da; SOUZA, John Brehmer de. Desenvolvimento e desenvolvimento sustentável: uma revisão contemporânea para pensar políticas públicas num ambiente de complexidade. In: Revista Jurídica Unicuritiba. vol. 01, n. 50, Curitiba, 2018, pp. 484-513. 
BRAGA, Isaque Trevisam. Por uma vivência planetária eco-lógica: diálogos interfilosóficos em torno de uma ética da responsabilidade. Dissertação (Mestrado em Filosofia) - PUC-SP. São Paulo, 2015.

BRASIL. Constituição da República Federativa do Brasil de 1988. Disponível em: http://www.planalto.gov.br/ccivil_03/constituicao/constituicao.htm. Acesso: 02 abr. 2019.

Transformando Nosso Mundo: A Agenda 2030 para o Desenvolvimento Sustentável. 2016.

Disponível

em http://www.itamaraty.gov.br/images/ed_desenvsust/Agenda2030completoportugus12 fev2016x.pdf. Acesso: 10 maio 2019.

CAMPOS, Ingrid Z. A. A análise histórica comparada internacional do princípio do desenvolvimento sustentável. In: Revista Jurídica Unicuritiba. Vol. 03, n. 48, Curitiba, 2017, pp. 169-198.

CAPRA, Fritjof; MATTEI, Ugo. A revolução Ecojurídica: o direito sistêmico em sintonia com a natureza e a comunidade. Tradução Jeferson Luiz Camargo. São Paulo: Editora Cultrix, 2018.

2006.

A teia da vida. Tradução Newton Roberval Eichemberg. São Paulo: Cultrix,

DIMOULIS, Dimitri; MARTINS, Leonardo. Teoria Geral dos Direitos Fundamentais.

5. ed. rev. atual. e ampl. São Paulo: Atlas, 2014.

GUATTARI, Felix. As três ecologias. 21. ed. Campinas: Papirus, 2012.

MAZZUOLI, Valério de Oliveira. A proteção internacional dos direitos humanos e o Direito internacional do meio ambiente. Revista Amazônia Legal de estudos sóciojurídico-ambientais. Cuiabá, Ano 1, n. 1, p. 169-196, jan.-jun. 2007.

Curso de direito internacional público. 9. ed. rev. Atual. E ampl. São Paulo: Editora Revista dos Tribunais, 2015.

MIGUEL, Amadeu Elves. Direitos humanos, sustentabilidade e desenvolvimento: aproximações e interdependência em face dos mega-projetos em Moçambique. Dissertação (Mestrado em Ciência Jurídica). Univali. Itajaí, 2014.

MÖLLER, Ana Karina Ticianelli; MUNIZ, Tânia Lobo. A proteção internacional dos direitos humanos e o direito internacional do meio ambiente: considerações iniciais. SCIENTIA IURIS, Londrina, v. 11, p. 259-277, 2007.

MORIN, Edgar. A via para o futuro da humanidade. Tradução de Edgard de Assis Carvalho e Mariza Perassi Bosco. Rio de Janeiro: Bertand Brasil, 2013. 
OLIVEIRA, Saullo Pereira de. A supremacia dos direitos humanos universais perante a soberania de um estado arbitrário. In: Revista da Escola Superior da Magistratura do Estado do Ceará - ESMEC. Fortaleza, vol. 11, p. 375-392, 2013.

ORGANIZAÇÃO DAS NAÇÕES UNIDAS NO BRASIL. Transformando Nosso Mundo: A Agenda 2030 para o Desenvolvimento Sustentável. 2015. Disponível em: https://nacoesunidas.org/pos2015/agenda2030/. Acesso em: 02 abr. 2019.

ORGANIZAÇÃO DOS ESTADOS AMERICANOS. Protocolo Adicional à Convenção Americana sobre Direitos Humanos em Matéria de Direitos Econômicos, Sociais e Culturais. Disponível em: http://www.planalto.gov.br/ccivil_03/decreto/D3321.htm. Acesso em: 10 abr. 2019.

PORTELA, Paulo Henrique Gonçalves. Direito Internacional Público e Privado: Incluindo noções de Direitos Humanos e de Direito Comunitário. 8. ed. rev. ampl. e atual. Salvador: JusPODIVM, 2016.

SARLET, Ingo Wolfgang; FENSTERSEIFER, Tiago. Princípios do direito ambiental. 2. ed. São Paulo: Saraiva, 2017.

SILVEIRA, Vladmir Oliveira da; PEREIRA, Taís Mariana Lima. Uma nova compreensão dos direitos humanos na contemporaneidade a partir dos objetivos de desenvolvimento sustentável (ODS). In: Revista Jurídica Cesumar. setembro/dezembro 2018 , v. 18, n. 3, p. 909-931

; SANCHES, Samyra Haydêe Dal Farra Naspolini. Direitos Humanos, Empresa e Desenvolvimento Sustentável. In: Direito e Desenvolvimento. João Pessoa: , v. 6, n. 12, p. 145-156. 